\title{
A UNIVERSIDADE COMO ESPAÇO PROMOTOR DE QUALIDADE DE VIDA: VIVÊNCIAS E EXPRESSÕES DOS ALUNOS DE ENFERMAGEM ${ }^{1}$ THE UNIVERSITY AS A PLACE THAT PROMOTES QUALITY OF LIFE: PERCEPTIONS AND EXPERIENCES OF NURSING STUDENTS \\ LA UNIVERSIDAD COMO UN ESPACIO PROMOTOR DE LA CALIDAD DE VIDA: VIVENCIAS Y EXPRESIONES DE LOS ALUMNOS DE ENFERMERÍA
}

\author{
Raquel Aparecida de Oliveira ${ }^{2}$, Maria Helena Trench Ciampone ${ }^{3}$
}

\begin{abstract}
Parte da tese "A Universidade como espaço promotor de qualidade de vida: vivências e expressões dos alunos de enfermagem", apresentada ao Programa Interunidades de Doutoramento em Enfermagem dos campi de São Paulo e Ribeirão Preto, na Universidade de São Paulo (USP), em 2005.

${ }^{2}$ Enfermeira. Professora do Departamento de Enfermagem do Centro de Ciências Médicas e Biológicas da Pontifícia Universidade Católica de São Paulo (PUC/SP).

${ }^{3}$ Enfermeira. Professora Associada do Departamento de Enfermagem de Orientação Profissional da Escola de Enfermagem da USP.
\end{abstract}

PALAVRAS-CHAVE: Enfermagem. Qualidade de vida. Educação em enfermagem.

KEYWORDS: Nursing. Quality of life. Nursing students. Nursing education. Estudantes de enfermagem.

RESUMO: O estudo teve como objetivo conhecer as percepções dos alunos de graduação em enfermagem, quanto à sua qualidade de vida. A abordagem adotada foi a qualitativa. Realizou-se cinco entrevistas individuais com questões abertas: para você, o que significa ter qualidade de vida; relate experiências pessoais ou observadas, em seu cotidiano como aluno, sobre aspectos que considera promotores e não promotores da sua qualidade de vida. A análise temática permitiu identificar as principais situações promotoras da qualidade de vida: experiências extracurriculares; relação professor-aluno; relacionamento entre os alunos. Os aspectos não promotores foram: a falta de acolhimento por parte de professores e enfermeiros de campo; a falta de integração com a equipe e com alunos de outros cursos do campus; e a carga horária excessiva para o aluno trabalhador. Evidencia-se o importante papel da educação como estratégia de medidas eficazes na busca da qualidade do cuidado.

ABSTRACT: The objective of this study was to know how graduation students from nursing school perceive their quality of life. The approach used was the qualitative mode. The data were collected through individual interviews with five students: to you what means having quality of life; report about personal experiences or experiences that you have observed in your daily routine as a student, about aspects that you consider may promote or not your quality of life. The theme analysis of these speeches made it possible to rescue main situations pointed as those that promote quality of life were: extra curricular experiences; the relationship professor-student; the relationship among the students. The main aspects pointed as those that do not promote quality of life were: the feeling of not being welcome by professors and field nurses; lack of integration with the team and students from other courses in the campus; the excessive overload for the student who besides studying also works. It is education represents the main strategy to implement effective measures for providing quality health care.

PALABRAS CLAVE: Enfermería. Calidad de vida. Estudiantes de enfermería. Educación en enfermería.
RESUMEN: El estudio tuvo como objetivo conocer las percepciones de los alumnos de graduación en enfermería, en cuanto a su calidad de vida. El abordaje adoptado fue cualitativo. Llos datos fueron colectados a través de la entrevista individual, con cinco alumnos, y se orientó por preguntas abiertas: para usted qué significa tener calidad de vida; relata experiencias personales u observadas en tu cotidiano como alumno, sobre que aspectos consideras como promotores y no promotores de su calidad de vida. El análisis temático de los discursos posibilitó aprehendio a las promotoras de la calidad de vida: experiencias extra-curriculares; relación profesor-alumno; relacionamiento entre los alumnos. Los aspectos señalados como no promotores fueron: la falta de acogida por parte de profesores y enfermeros del campo; la falta de integración con el equipo y con los alumnos de otros cursos del campus; la carga horaria excesiva para el alumno que trabaja. Los resultados permitieron proponer estratégias viables para la mejoría de la búsqueda de un cuidado com calidad a la clientela.
Endereço: Raquel Aparecida de Oliveira R. Visconde de Cairu, 694, Bl. 04, Ap. 31 18.040-350 - Mangal, Sorocaba, SP. E-mail: raquel@sorocaba.pucsp.br
Artigo original: Pesquisa

Recebido em: 11 de novembro de 2005. Aprovação final: 04 de maio de 2006. 


\section{INTRODUÇÃO}

$\mathrm{O}$ interesse em realizar este estudo adveio da prática profissional como docente em Curso de Graduação em Enfermagem. Percebemos que, no decorrer do exercício desta função, observamos os comportamentos e discursos dos alunos, despertando-nos a atenção para a necessidade de avaliar se, durante a formação profissional na Universidade, esse espaço é percebido como promotor ou não de vivências que contribuem para qualidade de vida dos estudantes.

Em revisão da literatura, constatou-se que as escolas têm se baseado na assimilação ou não, de conteúdos informativos e menos no processo formativo. ${ }^{1}$

No contexto de uma profissão onde a própria tarefa, que é o cuidar, é bastante ansiogênica, seria importante que a formação profissional favorecesse o processo de auto-conhecimento e apoio para trabalhar, ainda enquanto estudante, os medos e ansiedades inerentes ao processo de cuidar de si e dos outros.

O papel do docente tem sido destacado como de grande importância quando este atua como facilitador para a adaptação do aluno aos primeiros contatos com o aprendizado prático da enfermagem. ${ }^{2}$

Conforme estudo, a falha dos docentes quanto ao apoio emocional, na continência, no saber ouvir, e na relação com o aluno, prevalecendo a atribuição de importância e o reforço dos aspectos cognitivos e técnicos envolvidos no ato do cuidado direcionado à clientela. $^{*}$

Outros autores, buscaram compreender se a preparação para o trabalho do futuro enfermeiro tem se constituído em um meio e instrumento de favorecimento do autocuidado e/ou da negação de si. ${ }^{3}$ As autoras perceberam que o autoritarismo e a sobrecarga horária exigida no curso favorecem a negação de si.

Inúmeros trabalhos que tomam como objeto de estudo o ensino de enfermagem, sobretudo os desenvolvidos nas últimas décadas, têm evidenciado a importância do cuidador em relação ao modo como esse cuida do outro. Torna-se visível, porém, no cotidiano de trabalho nas instituições de saúde, o quanto o cuidador profissional, de modo geral, não valoriza o ser cuidado, muitas vezes negligenciando o cuidado à sua própria saúde.
A fragmentação dos processos de trabalho esgarça as relações entre os diferentes profissionais da saúde e entre esses e usuários; o trabalho em equipe, bem como o preparo e disposição pessoal dos profissionais para lidarem com a dimensão subjetiva presente nas práticas de atenção em saúde, tem deixado a desejar.

O trabalho em saúde é complexo e exige reflexão, ou seja, que as decisões sejam tomadas de modo articulado pelos vários saberes profissionais pautados em diferentes conhecimentos, que devem ser mediados pela dimensão ética e política.

Torna-se fundamental ampliar a qualificação dos trabalhadores em saúde, seja na dimensão técnica (aprender a fazer e conhecer), como na dimensão ético-política (dimensão do aprender a conviver e ser), da comunicação, das inter-relações pessoais, viabilizando a atenção integral dos sujeitos assistidos, exigências presentes tanto nos discursos dos órgãos formadores, quanto no mercado de trabalho.

No contexto das políticas da educação brasileira, as mudanças no cenário da formação profissional, refletem as exigências da LDB de 1996, Lei 9394/96. ${ }^{4}$ Permitiram-se contornos diferenciados nos perfis de formação profissional, que tem gerado várias propostas de reformas no ensino superior. A LDB assegura à Instituição de Ensino Superior maior flexibilidade na organização curricular dos cursos, imprimindo, contudo, a necessidade de uma profunda revisão de princípios e tradições de ensino, que burocratizam os cursos e se revelam incongruentes com as tendências contemporâneas de considerar a formação, em nível de graduação, como uma etapa inicial da formação continuada. Neste cenário, surgem as Diretrizes Curriculares do Curso de Graduação em Enfermagem publicada no Diário Oficial $n^{\circ} 215$ de 9 de novembro de $2001 .^{5}$

As Diretrizes Curriculares dos Cursos de Graduação da área da Saúde permitem que os currículos propostos possam construir perfil acadêmico e profissional com competências, habilidades e conteúdos, dentro de perspectivas nacionais e internacionais, capazes de atuar com qualidade, eficiência e resolutividade, no Sistema Único de Saúde (SUS), no contexto da Reforma Sanitária Brasileira.

Com base nesse contexto, após ampla discussão, com a participação da ABEN e o CNE, a Comissão de Especialistas de Ensino de Enfermagem insti-

\footnotetext{
* Ciampone EEL. Cuidando do cuidador em processo de formação: vivendo uma experiência no âmbito do ensino da graduação em enfermagem: relatório de pesquisa [mimeografado]. São Paulo: 2000.
}

Texto Contexto Enferm, Florianópolis, 2006 Abr-Jun; 15(2):254-61. 
tui as Diretrizes Curriculares para a Enfermagem, onde se define a formação segundo os paradigmas de um perfil profissional crítico e reflexivo com competência técnica- ética-política-social-educativa, que lhe permita atuar com segurança e propriedade tanto na promoção da saúde, como na prevenção e reabilitação, interagindo de forma efetiva com a sociedade, apresentando uma capacidade de liderança e muita sensibilidade para lidar com os problemas de saúde da comunidade. Almeja-se que o profissional possa trabalhar com equipes multidisciplinares e também em serviços socializados.

A discussão sobre o processo de formação dos cuidadores profissionais é, portanto, fundamental. As Diretrizes para a Educação em Enfermagem no Brasil estão sendo amplamente discutidas pelas instituições formadoras, que devem redefinir seus Projetos Político-Pedagógicos.

Partindo desses pressupostos, que apontam para a necessidade de projetos que envolvam o sistema formador como um espaço articulador de discussões a respeito de qualidade de vida, incluindo a do futuro profissional para o trabalho, justifica-se a elaboração da presente investigação. A hipótese formulada é que o objeto deste estudo - a formação dos profissionais enfermeiros compreende o desenvolvimento de competências que envolvem uma permanente correlação e interação entre a dimensão pessoal/singular, profissional/particular e social/estrutural, que determinam e podem gerar tanto processos de potencialização da qualidade de vida, como processos destrutivos da mesma, comprometendo a saúde física e mental do profissional e futuramente, a qualidade da assistência por eles prestada aos indivíduos, a famílias e comunidades. Nesse sentido, questionamos: a Universidade tem sido ou não um espaço para aprendizagem e vivência da qualidade de vida dos futuros enfermeiros?

\section{OBJETIVOS}

Considerando o processo de formação vivenciado, particularmente, pelos estudantes de graduação em enfermagem da Pontifícia Universidade Católica de São Paulo (PUC/SP), e suas relações com o processo de construção da qualidade de vida, os objetivos do presente estudo foram:

\section{Objetivo geral}

Identificar as percepções que os estudantes de graduação em enfermagem da PUC/SP, têm em rela- ção à qualidade de vida no trabalho, tendo em vista as experiências vivenciadas no processo de formação.

\section{Objetivos específicos}

- Identificar a compreensão que os estudantes da PUC/SP têm sobre a própria qualidade de vida.

- Analisar as principais demandas por eles evidenciadas no resgate das situações vividas e nos direcionamentos e estratégias de enfrentamento utilizadas que geram melhoria da sua qualidade de vida.

\section{METODOLOGIA}

A base metodológica que fundamentou este estudo sobre a qualidade de vida na formação dos futuros enfermeiros foi a pesquisa qualitativa, pois a mesma permite o acesso à intersubjetividade presente no propósito de revelar a compreensão que o aluno tem em relação à sua vivência, durante a formação, quanto à qualidade de vida.

Foram convidados para participar do primeiro momento do estudo cinco estudantes da quarta série do Curso de Graduação em Enfermagem do Centro de Ciências Médicas e Biológicas da PUC/SP. Cabe destacar que o número de colaboradores que participaram da coleta foi definido pelo critério de representatividade das experiências presentes nos discursos. Estes participantes foram por nós considerados porta-vozes do grupo ao qual pertencem.

Os dados foram coletados através de entrevista individual semi-estruturada, com o intuito de favorecer ao entrevistado a possibilidade de discorrer sobre o tema proposto, sem direcionar repostas ou condições pré-fixadas pelo pesquisador, como um meio de acessar tanto conteúdos voltados ao posicionamento próprio quanto às percepções e significados atribuídos ao vivido do estudante em relação à sua qualidade de vida.

A autorização para realizar as entrevistas com as estudantes foi precedida pelo encaminhamento e aprovação do projeto de pesquisa pelo Comitê de Ética. Tivemos o cuidado de explicar os objetivos e o caráter sigiloso dos sujeitos participantes da pesquisa, no procedimento das entrevistas. As estudantes foram devidamente esclarecidas sobre a utilização da informação e assinaram o consentimento informado, conforme preconizado nas determinações constantes na Resolução n. 196/96 do Conselho Nacional de Saúde. ${ }^{6}$

A entrevista pautou-se em um roteiro constando de três questões abertas relacionadas ao significa- 
do sobre qualidade de vida e, em seguida, solicitávamos relatos de experiências pessoais ou observadas em seu cotidiano sobre aspectos promotores e não promotores da qualidade de vida. Os dados foram registrados por meio de gravação e transcritos na íntegra.

Os dados foram sistematizados considerandose as principais etapas da análise temática, uma das técnicas de Análise de Conteúdo do discurso. ${ }^{7} \mathrm{O}$ processo de tratamento dos dados foi realizado em duas fases: na primeira, realizamos uma pré-análise, pautada na "leitura flutuante" do material, chegando ao contato exaustivo com os dados, até atingir uma "impregnação" pelo conteúdo. $\mathrm{Na}$ segunda fase, realizamos a exploração do material, recortando os dados e compilando-os de acordo com os conteúdos, a partir das unidades de significados (categorias e subcategorias). Para esta fase, elaboramos quadros individuais e posteriormente, um quadro geral, para cada uma das questões disparadoras do discurso.

A análise temática pautou-se no processo de formação dos futuros enfermeiros, visualizando-se como finalidade, compreender o pensar, o sentir e o agir, que norteiam esses alunos, na construção cotidiana da sua qualidade de vida. Esta análise foi viabilizada por interpretações ancoradas no discurso ao conhecimento produzido tendo como categorias de análise a totalidade e dinamicidade e a práxis que permeiam o ensino de enfermagem numa perspectiva histórica e humanística.

\section{RESULTADOS}

As estudantes referiam-se à percepção de qualidade de vida como um equilíbrio entre a vida profissional e pessoal. Relataram com maior facilidade as vivências de situações não promotoras de qualidade de vida. Afirmaram que o apoio psicológico, as crenças, os valores e a religião pessoal constituem-se em bases para manter o equilíbrio.

Resgataram a lembrança de momentos de vivência, em algumas disciplinas, como sendo promotoras de qualidade de vida para si e para o cliente. As situações não promotoras de qualidade de vida foram expressas por relatos de convívio com alguns docentes e pela recepção que consideraram inadequada por parte dos enfermeiros de campo. As dificuldades relativas à estrutura física e material, nas instituições onde estagiaram e a falta de integração entre a equipe médica e de enfermagem, foram também citadas como situações não promotoras de qualidade de vida.
Outro aspecto considerado como não promotor de qualidade de vida foi relacionado a situação do estudante trabalhador e a excessiva carga horária do curso. Revelaram, ainda, que as situações de tensão e conflito inerentes ao modo como lidar com o descaso da equipe médica, descaso do familiar em relação ao paciente e a morte, geram sentimentos de impotência e de solidão nos estudantes e constituem-se em aspectos que desfavorecem a qualidade de vida. A valorização e reconhecimento do cuidado prestado pelo estudante ao paciente, familiares, equipe e professores são percebidos como situações promotoras de qualidade de vida.

\section{Sobre os significados de qualidade de vida}

As estudantes percebem qualidade de vida como poder fazer o que gostam e terem tempo para o trabalho e para a vida pessoal (família, lazer e o cuidado de si), conforme ilustra o trecho da fala: ter qualidade de vida no trabalho significa em primeiro lugar a pessoa ter que gostar do que faz, se ela não gosta, ela não vai ter vontade de fazer o trabalho, vai fazer só por obrigação, pelo dinheiro, ou por outra coisa, se ela gosta do que faz ela vai se sentir melhor (Ana).

Para manter-se em equilíbrio, sem ter sobrecarga excessiva e estresse, apontam o lazer como atividade terapêutica, o apoio psicológico, a rede de relações familiares, destacando a importância de ter fé e uma religião, como meios de sustentação.

Porque qualidade de vida é isto, não viver só em função do trabalho, você não pode se sobrecarregar, não pode se estressar, e eu acho que para evitar isto, precisa ter uma atividade terapêutica, ter família, apoio psicológico, em todos, mas eu acho que é muito importante, ter uma religião, uma fé (Clara).

Percebem, também, que as estruturas organizacionais, bem como as relações interpessoais, devem favorecer as condições adequadas para a realização do trabalho. O ambiente harmonioso entre as pessoas e a oportunidade de uma educação continuada oportunizada aos profissionais, são também valorizados como aspectos significativos para a qualidade de vida.

[...] um lugar em que tenha uma estrutura adequada, para que você possa exercer suas funções adequadamente. Não só o local, mas, que ela possa ter estrutura física e também a parte burocrática tem que oferecer condições (Julia).

[...] ab! Que também tenha espaço para o profissional poder se manter atualizado, freqüentar cursos, congressos [...]. Isto reflete na qualidade de vida, porque o profissional que não se atualiza não pode prestar uma assistência adequada (Maria). 


\section{Sobre as situações promotoras de qualidade de vida}

As aulas de Antropologia, Psicologia, Psiquiatria e atividades acadêmicas, foram referidas pelas estudantes como promotoras de qualidade de vida.

$\mathrm{Na}$ aula de psiquiatria, a professora sempre fala que precisa cuidar da mente [...] en estava muito estressada [...] isto tudo me ajudou muito a pensar em mim, a falar o que eu penso e buscar o que en quero mesmo. Mudei bastante (Ana).

[...] matérias como também, Psicologia, Antropologia, que fazem parte das ciências humanas, elas ajudam a conhecer mais não só o paciente, como a gente também, e entender melhor a vida (Ana).

[...] alguns trabalhos que a faculdade far, a Semana da Enfermagem, que trata um pouco da parte psicológica, que fala da bumanização, acho que isto abre um pouco a nossa cabeça também [...] promovendo a qualidade de vida (Clara e Luana).

As estudantes enumeram várias vivências que evidenciam a percepção quanto à relação professoraluno, como possível promotora de qualidade de vida.

Em alguns estágios, não todos, en vi muita gente trabalhando com gosto, alguns professores também. Vocêpercebe que eles tentam passar seguranca, entendem seus problemas e procuram dar um certo apoio e eu penso que isto ajuda bastante (Clara).

Alguns professores [...] você percebe que fazem o que gostam e de certa forma incentivam e estimulam você $[. .$.$] ela$ ensina com alegria, com entusiasmo, ela respeita o paciente, fala baixo, não grita, trata bem os pacientes, os auxiliares, o astral dela é bom (Clara).

As representações sobre ter cidadania e conquistar os direitos com consciência dos deveres, também se constitui em tema, quando se indagou sobre as situações promotoras de qualidade de vida.

Eu penso que qualidade de vida tem muito haver com cidadania, porque você exercendo sua cidadania você vai ter uma qualidade de vida melhor. Lutar por aquilo que a gente acredita, buscar nossos direitos, exercer nossos deveres, respeitar, saber o seu espaço. Eu penso que cidadania é ligada com qualidade de vida (Julia).

Outro tema recorrente foi o apoio advindo dos relacionamentos. Nas entrevistas houve o relato de situações onde o apoio recebido pelo estudante oferecido pela equipe do setor onde estagiava ou não, foi significativo dentre as experiências promotoras e não promotoras de qualidade de vida.

[...] é ser bem recebido no setor. Poder contar com os enfermeiros, que eles dêem atenção, porque às vezes a gente quer perguntar alguma coisa e não consegue nem ser ouvido (Luana).
Quanto ao resultado do cuidado prestado, as estudantes citaram que, quando o cuidado prestado resulta em melhoria dos pacientes ou grupos da comunidade, estes se sentem gratificados e isso também promove a qualidade de vida.

Ab! Mas é gostoso você vê alguém que está ali encolbida, deprimida e você consegue animar esta pessoa! Eu gosto! Esta na alma, você deitar e dormir, você está até mais leve, já inclui o paciente nas suas orações (Maria).

Algumas situações vividas nos estágios são relatadas como desencadeantes de mudança de atitude no sentido de valorização da vida. Nesse sentido, percebem que determinadas situações de estágio mudaram seus valores, fazendo com que reconhecessem riscos e a importância de cuidar de si, sendo este fator considerado como promotor de qualidade de vida.

[...] depois que en fiz estágio no Pronto Socorro, eu vi muitos acidentes de moto, então, talvez tenha melhorado a minha qualidade de vida, porque eu não vou mais andar de moto (Maria).

\section{Sobre as situações não promotoras de quali- dade de vida}

Relatam que a introdução no hospital e o contato com os doentes e a realização de procedimentos geram angústia, medo e às vezes traumatizam o aluno, se o docente não for continente.

Ab! Os estágios, né. No primeiro ano, nossa! O medo da Professora $Z$ que pelo amor deDeus! Então no começo foi muito difícil, eu não sei, en acho que se a disciplina não tivesse tanto procedimento, deveria ter mais sensibilidade por parte da professora, eu tinha muito medo de fazer um procedimento errado, de ter uma reclamação da professora, então eu sentia muito medo de chegar. Talvez se fosse de outra forma en teria aproveitado mais os estágios. Eu ficava com medo mesmo, a disciplina me agonizava muito e eu ficava com muito medo. Me estresso, eu tinha medo, mas assim, o bom é que eu não desisti da profissão (Ana).

As atitudes negativas do professor demonstra falta de carinho, tolerância, de paciência e de ética com os alunos. Nessa fase inicial da aprendizagem é percebido pelas estudantes como não promotor de qualidade de vida.

[...] porque tem professores que não têm muita ética, não têm paciência. As vežes ele chama a atenção em frente do paciente, eu acho que isto é uma situação muito desagradável, principalmente se for no inicio do curso, que a pessoa está crua ainda, este é um ponto negativo (Clara). 
A gente respeita muito a profissão de professor [...] mas eu acho que se tivesse um pouco mais de educação ia melhorar muito a qualidade de vida (Luana).

O relacionamento entre os estudantes de enfermagem e destes com alguns professores e estudantes de outros cursos, também foi mencionado enquanto situação não promotora de qualidade de vida.

[...] falta um pouco de relacionamento, amizade mesmo, entre as faculdades, por exemplo: enfermagem, medicina, biologia. Eu penso que tem muito preconceito em relação a isso (Clara).

As atitudes negativas do enfermeiro dos serviços de saúde que são cenários de ensino-aprendizagem, demonstrando desatenção ao paciente, resulta em desestímulo para o estudante, sendo interpretado como descaso em relação ao cuidado. Para eles o enfermeiro de campo é, de certo modo, um modelo ou um antimodelo.

Ela não se preocupa com a equipe, ela nem sabe o nome dos pacientes, ela não faz. assistência direta, nem prescrição de enfermagem, nem nada (Clara).

A carga horária do curso e as condições de aprendizagem para o estudante trabalhador, também foram lembradas como não promotoras de qualidade de vida.

[...] porque en estava trabalhando, até que, eu podia ter rendido, produzido coisas melhores, en gostaria de ter participado em um trabalho cientifico na faculdade, mas o meu tempo para pesquisar fora foi muito escasso (Luana).

$\mathrm{Na}$ nossa sala acho que tem mais uns 10 alunos que trabalham, por isto que eu vejo tem aluno que se doa tanto que chega a adoecer (Maria).

Os relatos onde as estudantes percebem a falta de suporte para o enfrentamento de situações vividas ocasionam sentimentos por eles nomeados como solidão, revolta e culpa.

[...] eu via a vida se esvair, e se fosse minha mãe, se fosse [...] acha que eu ia ficar parada? Mas nunca! Porque eu me senti culpada de não ter feito alguma coisa [...] e ali na emergência, ainda mais o aluno, fica desesperado [...] (Julia).

Gerou sentimentos de revolta, sentimentos de muitos porquês sem respostas, isto que é mais triste! (Julia).

\section{DISCUSSÃO}

O conceito de qualidade de vida, apesar de ser amplamente utilizado nos últimos anos e ainda hoje, não tem uma definição abrangente o suficiente para que seja aceita universalmente. É possível afirmar que o conceito de qualidade de vida vem sofrendo modifi- cações que acompanham a dinâmica dos diferentes contextos sociais com suas diferenças culturais, suas prioridades e crenças.

$\mathrm{Na}$ busca de uma definição que abarcasse maior amplitude, a Organização Mundial da Saúde define como qualidade de vida "a percepção do indivíduo de sua posição na vida no contexto da cultura e sistemas de valores nos quais ele vive e em relação aos seus objetivos, expectativas, padrões e preocupações". 8:3-4 Essa definição tem constituído em referência comum, na maioria dos estudos sobre a temática.

As percepções sobre os significados de qualidade de vida das estudantes de enfermagem contemplaram elementos que coincidem com as definições encontradas na literatura.

As estudantes identificam projeções para o futuro profissional, mencionam a questão da carga horária excessiva de trabalho; a remuneração insuficiente e o mercado de trabalho que exige produtividade. Outro ponto ressaltado é a insegurança percebida pela não valorização das atividades executadas pelos estudantes durante a formação, por parte de outros profissionais; a falta de acolhimento dos colegas enfermeiros em relação às dificuldades vividas no início da profissão; os conflitos gerados a partir do enfrentamento de situações profissionais em diferentes contextos vividos durante a formação, a preocupação em dar continuidade a uma assistência de qualidade para os clientes e o desejo de serem profissionais diferentes dos modelos que encontram no campo prático.

Nos aspectos de projeção para o futuro identificado pelas estudantes, argumenta-se que as abordagens de Qualidade de Vida no Trabalho (QVT), na maioria das vezes, enfatizam dois aspectos antagônicos. $^{9} \mathrm{O}$ primeiro se refere às reivindicações dos trabalhadores, com prioridade ao aspecto de bem-estar e satisfação no trabalho enquanto meta que termina em si mesma. O segundo, com ênfase nos efeitos da QVT sobre a produção e produtividade, em defesa dos interesses da empresa que atendem aos interesses do capital. E ainda, que outras abordagens associam qualidade de vida no trabalho a aspectos mais amplos como: condição de cidadania, de participação e democratização nos ambientes de trabalho.

Considerando o momento produtivo na determinação da qualidade de vida dos estudantes de enfermagem durante a formação, um perfil promotor é confrontado com um perfil não promotor de qualidade de vida. Esse perfil protetor é identificado principalmente quando: há um espaço para reflexão nas disciplinas; 
quando o professor têm uma postura continente; quando são apoiados pela equipe no local de estágio; quando podem buscar seus direitos e exercer seus deveres; quando percebem o resultado do cuidado prestado e mudam de atitudes reconhecendo riscos e a importância de cuidar de si.

O perfil não promotor de qualidade de vida é percebido pelas estudantes nos seguintes aspectos: na introdução no ambiente hospitalar em contato com os doentes e na realização de procedimentos geradores de angústia, medo e trauma; na postura do professor, nas atitudes negativas do enfermeiro de campo; na falta de integração entre os estudantes e outros cursos da Universidade; falta de suporte para enfrentamento das situações vividas; na carga horária excessiva do curso e nas condições de aprendizagem para o aluno trabalhador. Este perfil gera processos de desgaste que comprometem a potencialidade de saúde e da vida dos estudantes de enfermagem.

Dessa forma, os estudantes de enfermagem vivem as contradições: experimentando de um lado, aspectos promotores da saúde e de outro, em oposição, os aspectos não promotores, gerados no momento de formação para o trabalho.

Nos aspectos promotores da qualidade de vida apontados pelas estudantes, é possível relacionar numa pesquisa, onde construiu-se e validou-se como um instrumento de medida de QVT para enfermeiras. ${ }^{10}$ Quanto ao significado de QVT, este foi associado à percepção de satisfação e de bem-estar em relação a diferentes aspectos presentes no trabalho. Em relação aos indicadores, a autora descreve como os mais importantes: o relacionamento interpessoal vertical e horizontal; o reconhecimento profissional, a preocupação com a qualidade do trabalho desenvolvido; a autonomia e estabilidade de emprego; a operacionalização do trabalho diário; as condições ergonômicas; a remuneração e recompensa; o tempo destinado ao trabalho e as oportunidades de crescimento profissional; a profissão e aspectos relacionados com o pessoal e o material disponível para trabalhar. ${ }^{10}$

As condições não promotoras de qualidade de vida foram representadas pelas dificuldades vivenciadas pelos colaboradores sendo comum, em parte, ao denominado como "Vivendo uma prova de fogo". ${ }^{2}$ Nesse estudo, a autora enfatiza que o início da aprendizagem prática de enfermagem é correspondente a uma vivência difícil e frustrante. Assim, a relação a ser desenvolvida com o professor deveria facilitar e não dificultar a interação, o ensino, o aprendizado e o querer ser enfermeiro, pois, mediante a relação com o campo, com os professores e profissionais, o estudante toma a decisão de continuar ou desistir da profissão.

A relação professor-estudante é considerada como geradora de medo, insegurança e angústia. Nesse aspecto, descreve-se como características dificultadoras da aprendizagem, segundo os colaboradores de seu estudo, também estudantes de graduação em enfermagem: a aprendizagem da teoria diferente da prática; o medo do professor; o professor que adia a resposta às perguntas; o professor que não responde às perguntas dos estudantes; o professor frustrado; a não familiaridade do professor com a especialidade; a insegurança do professor quanto ao desenvolvimento do estudante e quanto ao conhecimento; o professor que não tem vivência com o estudante e as dificuldades dos estudantes que não trabalham na área. ${ }^{11}$

Considerando que a qualidade de vida dos estudantes de enfermagem constitui-se em diferentes cenários e que as situações na formação do enfermeiro que determinam e podem gerar tanto processos potencializadores de qualidade de vida, como processos destrutivos da mesma, comprometendo a saúde física e mental do futuro profissional é que justifica a necessidade de preparo dos futuros profissionais de saúde e dos docentes para o desenvolvimento do cuidado de si, como precedente da condição para o cuidar de outros.

As relações de cuidado acontecem na nossa vivência diária, na família, no trabalho, no convívio social em geral. Por isso, entendem que o cuidar é uma maneira de ser de cada um incorporado a um comportamento co-participante de progressão individual e/ou coletiva aglutinados às dimensões éticas e morais. ${ }^{12}$

Desta forma, as autoras enfatizam que "há que se pensar no cuidador, pois ele também precisa ser cuidado, e, neste momento, ele se transforma num ser cuidado, não sendo mais um ser que cuida, com todas as relações de cuidado a que tem direito". ${ }^{12: 81}$

O período de formação constitui-se um tempo, onde os alunos vivem a experiência de se conhecer como parte do ir se preparando para ser profissional. Muitas vezes, a sensibilidade estando excluída das relações interpessoais, acarreta perda de um canal importante para acessar a leitura da realidade, para a compreensão empática do outro.

Neste sentido, considero que, as formas de aprendizagens devem implicar na exploração das vivências de ensino de maneira crítica, contribuindo, assim, para 
o auto-conhecimento do aluno. Tal reflexão passa pela análise do papel do futuro enfermeiro, nas instituições, nas suas atividades em relação ao trabalho na equipe multiprofissional, seu posicionamento quanto as relações de poder, relações com o usuário e com sua própria saúde.

O cuidar, como essência da enfermagem, oportuniza a vivência de práticas pelo contato direto com seres humanos em processo de sofrimento, coloca o estudante e professor diante de seus próprios conflitos e frustrações, sendo assim, é importante que o professor proporcione momentos de aconselhamento e escuta, de modo que o aluno possa trabalhar situações de transferência e contrareferência e assim possa elaborar as vivências que vão acontecendo no trabalho de aprender a cuidar de si e dos outros.

Desta forma, o aconselhamento aborda os aspectos interpessoais dos atendidos e resgata a preocupação humanizadora para com estes aos aspectos pessoais de quem atende. Para, a capacidade de aconcelhamento é importante para favorecer relações saudáveis do profissional com os clientes, o que deduz que o profissional esteja atento a sentimentos, pensamentos e comportamentos; que esteja atento ao que esteja acontencendo entre eles naquele momento e a eventos externos à relação que podem estar influenciando no que está acontecendo. ${ }^{13}$

Este estudo vem justificar a necessidade de oportunizar espaços de aprendizagens formalizados durante a formação que permitam atender as necessidades de educar para o cuidar de forma efetiva.

Consideramos a importância do desenvolvimento de pesquisas que testem e avaliem intervenções relacionadas à promoção de qualidade de vida para os futuros enfermeiros, pois, atentar para a qualidade de vida exige de todos nós a consciência de cultivar o interesse pela nossa vida, pela vidas das outras pessoas, trata-se de um compromisso em aperfeiçoar a arte de viver, de educar e cuidar.

\section{REFERÊNCIAS}

1 Ciampone MHT. Grupo operativo: construindo bases para o ensino e a prática na enfermagem [tese]. São Paulo (SP): Escola de Enfermagem da USP; 1998.

2 Ângelo M. Vivendo uma prova de fogo: as experiências iniciais da aluna de enfermagem [tese]. São Paulo: Instituto de Psicologia da USP; 1989.
3 Oliveira ICS, Fernandes JF, Lunardi VL. Como a futura enfermeira está se cuidando e vem sendo cuidada no processo de graduação. Texto Contexto Enferm. 2000 Set-Dez; 9 (3): 133-52.

4 Brasil. Lei No 9394, de 20 de dezembro de 1996. Estabelece as diretrizes e bases da educação nacional. Diário Oficial da República Federativa do Brasil, 23 Dez 1996. No 248. p.27.833-41.

5 Ministério da Educação (BR), Conselho Nacional de Educação. Resolução No 3, de 7 de novembro de 2001: diretrizes curriculares nacionais do curso de graduação em enfermagem [acesso em 2001 Nov 09]. Brasília: O Conselho; 2001. Disponível em: http://www.in.gov.br

6 Ministério da Saúde (BR), Conselho Nacional de Saúde, Comitê Nacional de Ética e Pesquisa em Seres Humanos. Resolução No 196, de 10 de outubro de 1996: diretrizes e normas regulamentadoras de pesquisas em seres humanos. Brasília (BR): O Conselho; 1996.

7 Minayo MCS. O desafio do conhecimento: pesquisa qualitativa em saúde. São Paulo/Rio de Janeiro: Hucitec; 1996.

8 Fleck MPA, Leal OF, Louzada S, Xavier M, Chachamovich E, Vieira $G$, et al.. Desenvolvimento da versão em português do instrumento de avaliação de qualidade de vida da OMS (WHOQOL-100). Rev. Bras. Psiquiatr. 1999 Jan-Mar; 21 (1): 19-28.

9 Matos E. Refletindo sobre a qualidade de vida no trabalho da enfermagem no Hospital Universitário. Texto Contexto Enferm.1999 Set-Dez: 8 (3): 27-43.

10 Carandina DM. Qualidade de vida no trabalho: construção e validação de um instrumento de medida para enfermeiras [tese]. São Paulo: Escola de Enfermagem da USP; 2003.

11 Cavalcante MB. Humanização no processo de formação de profissionais de saúde: experiências de alunos do curso de graduação de Enfermagem [tese]. São Paulo: Escola de Enfermagem da USP; 2003.

12 Costenaro RGS, Lacerda MR. Quem cuida de quem cuida? quem cuida do cuidador? Santa Maria: Centro Universitário; 2002.

13 Martins MCFN. Humanização das relações assistenciais: a formação dos profissionais de saúde. São Paulo: Casa do Psicólogo; 2001. 